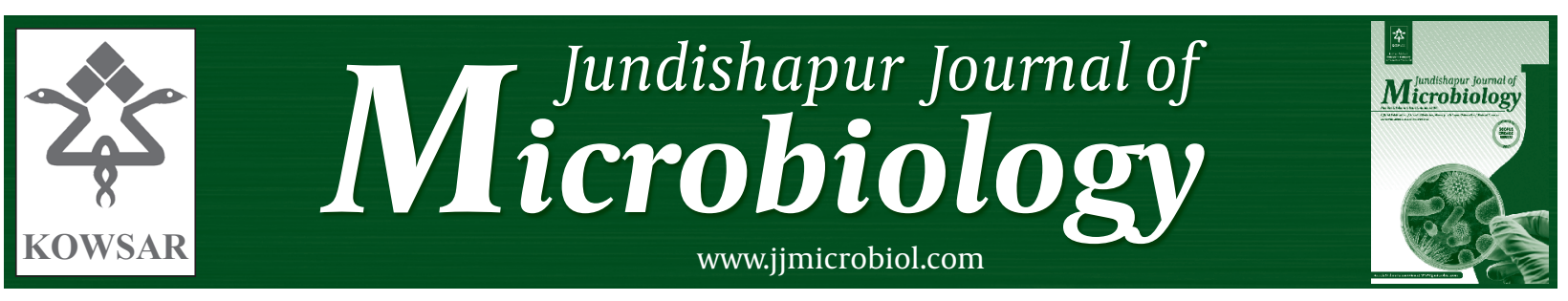

\title{
The Prevalence of Bacteria Isolated From Endotracheal Tubes of Patients in Golestan Hospital, Ahvaz, Iran, and Determination of Their Antibiotic Susceptibility Patterns
}

\author{
Azar Dokht Khosravi ${ }^{1,2}$, Najmeh Parhizgari ${ }^{1^{*}}$, Effat Abbasi Montazeri ${ }^{1}$, Alireza Mozaffari ${ }^{3}$, \\ Fariba Abbasi ${ }^{4}$ \\ ${ }^{1}$ Department of Microbiology, School of Medicine, Ahvaz Jundishapur University of Medical Sciences, Ahvaz, IR Iran \\ ${ }^{2}$ Infectious and Tropical Diseases Research Center, Ahvaz Jundishapur University of Medical Sciences, Ahvaz, IR Iran \\ ${ }^{3}$ Internal Medicine Ward, Golestan Teaching Hospital, Ahvaz Jundishapur University of Medical Sciences, Ahvaz, IR Iran \\ ${ }^{4}$ Central laboratory, Golestan Teaching Hospital, Ahvaz Jundishapur University of Medical Sciences , Ahvaz, IR Iran
}

\section{A R T I C L E I N F O}

Article type:

Original Article

Article history:

Received: 24 Feb 2012

Revised: 11 Apr 2012

Accepted:15 May 2012

\section{Keywords:}

Tracheal Tubes

Antibiotic Susceptibility

Bacteria

Pseudomonas

Enterobacter spp.

\begin{abstract}
A B S T R A C T
Background:Nosocomial infections including infections of surgical wounds, urinary tract and lower respiratory tract infections are a major public health problem in hospitals worldwide. Bacterial infections in the lower respiratory tract especially due to Gram negative bacilli, has remained a major complication of tracheal intubation in patients requiring ventilator equipments.

Objectives: The aim of present study was to determine the presence or absence of bacterial infections in tracheal tubes and determination of their antimicrobial susceptibility patterns.

Materials and Methods: In this study, specimens were collected from tracheal tubes of patients with endotracheal aspiration. The specimens were microbiologically investigated and the isolated bacteria were identified by using standard cultural and biochemical tests. The antibiotic susceptibility testing was then performed on the isolates by disc diffusion method according to CLSI guideline.

Results: In total, 278 specimens had positive culture with 508 isolates. Based on the bacteriology results, Enterobacter spp. with 209 cases (41.14\%) were the most prevalent genera isolated from positive cultures. The number and frequency of other isolated bacteria were as follow: Pseudomonas aeruginosa 78 (15.35\%), E. coli 71 (13.97.2\%), coagulase negative staphylococci 75 (14.76\%), Staphylococcus aureus 71 (13.97\%), and proteus spp. 4 (0.79\%). Antimicrobial susceptibility testing revealed that the most resistant Gram negative isolate was P. aeruginosa with highest resistance against cefixime (70.8\%), and coagulase negative staphylococci were the most resistant Gram positive isolates with highest resistance against oxacillin (84.2\%).

Conclusions: In conclusion, this survey indicates the emergence of antibiotic resistant infections in the studied hospital. So, there is a need to improve the effectiveness of integrated infection control programs to control and manage nosocomial infections caused by highly resistant organisms.
\end{abstract}

Published by Kowsar Corp, 2013. cc 3.0.

Implication for health policy/practice/research/medical education:

The findings of this study reflect the emergence of antibiotic resistant infections in our hospital wards especially ICU and NICU. This provides the useful information for HAI surveillance in teaching hospitals to control and manage nosocomial infections caused by highly resistant organisms.

${ }^{*}$ Corresponding author: Najmeh Parhizgari, Department of Microbiology, School of Medicine, Ahvaz Jundishapur University of Medical Sciences, Postal code: 61335Ahvaz, IR Iran. Tel:+98-6113330074, Fax:+98-6113332036, E-mail: parhizgarin@gmail.com, azarkhosravi69@gmail.com

DOI: $10.5812 / j \mathrm{jm} .4583$

(C) 2013 Ahvaz Jundishapur University of Medical Sciences; Published by Kowsar Corp.

This is an Open Access article distributed under the terms of the Creative Commons Attribution License (http://creativecommons.org/licenses/by/3.0), which permits unrestricted use, distribution, and reproduction in any medium, provided the original work is properly cited. 
Please cite this paper as:

Khosravi AD, Parhizgari N, Abbasi Montazeri E, Mozaffari A, Abbasi F. The Prevalence of Bacteria Isolated From Endotracheal Tubes of Patients in Golestan Hospital, Ahvaz, Iran, and Determination of Their Antibiotic Susceptibility Patterns. Jundishapur J Microbiol. 2013;6(1):67-71. DOI:10.5812/jjm.4583

\section{Background}

Nosocomial infections or hospital-acquired infections (HAI), are a major public health problem in hospitals worldwide, accompanied by high rate of morbidities and mortality among hospitalized patients (1). The burden of HAI is already substantial in developed countries, where it affects from $5 \%$ to $15 \%$ of hospitalized patients in regular wards and as many as $50 \%$ or more of patients in intensive care units (ICUs).In developing countries, the magnitude of the problem has remained underestimated or even unknown mostly because HAI diagnosis is complex and surveillance activities to guide interventions require expertise and enough resources (2).

The most frequent nosocomial infections are infections of surgical wounds, urinary tract infections and lower respiratory tract infections. According to WHO study, the highest prevalence of nosocomial infections occurs in intensive care units and in acute surgical and orthopaedic wards. Infection rates are higher among patients with increased susceptibility because of old age, underlying diseases, or chemotherapy (3).

Invasive medical procedures in the intensive care units remarkably increase the risk of such infections. Ventilator associated pneumonia and catheter associated urinary tract infections have been shown to cause the greatest risk to patients safety. Moreover, the use of different kinds of catheters, endotracheal tubes, supplying apparatuses and surgeries are the most common ways for transmission of nosocomial infections $(4,5)$. Colonization of the respiratory tract is very common in intubated patients requiring intensive care and in most instances leads to the increase of infection $(1,6)$. Intubation with mechanical ventilation increases the risk of pneumonia 6 to 20 folds more among patients and is associated with crude mortality rates of $20 \%$ to $40 \%(7,8)$.

Tracheal colonization by significant number of potential pathogenic bacteria predispose patients to super infection with presentation of fever, lower respiratory signs and symptoms, and an increase in the number and proportion of polymorphonuclear leukocytes in the sputum (9). In consequence, nosocomial pneumonia is a common and a life threatening problem among seriously ill patients who are mechanically ventilated. The incidence varies from $9 \%$ to $68 \%$ with a high fatality rate ranging from $50 \%$ to $80 \%$, especially when it is caused by antibiotic-resistant bacteria. This emergence of antibiotic-resistant microorganisms in critically ill patients represents a new challenge for intensive care physicians (10). Bacterial infection due to Gram negative bacilli in the lower respiratory tracts remains a main complication of tracheal intubation in patients requiring ventilator equipments (6).Widespread use of antibiotics in intensive care units is a potential cause of the emergence of nosocomial infections caused by antibiotic-resistant Gram-negative bacteria(11).

The percentages of Healthcare Associated Infection (HAIs) and bacterial resistance in developing countries are 3 to 5 times higher than international standards. HAIs increase the length of stay (10 days), costs (US $\$ 5000$ to US $\$ 12,000$ ), and mortality by 2 to 3 folds (12).

\section{Objectives}

The aim of present study was to determine the presence or absence of bacterial infections in tracheal tubes and determination of their antimicrobial susceptibility patterns.

\section{Materials and Methods}

This cross sectional study was performed from March 2009 to March 2010 in Golestan teaching hospital in Ahvaz, south west of Iran. Specimens were collected from tracheal tubes of patients with endotracheal aspiration, who had clinical manifestations of pneumonia and were admitted to different wards of general Intensive Care Unit (ICU), Neurologic Intensive Care Unit (NICU), Neurology, pediatrics ICU, Neurosurgical ICU and transplant wards. The length of stay of patients in mentioned wards was at least two weeks prior to sampling. Tracheal tube samples were inserted in a sterile tube and transferred to the laboratory where inoculated into thioglycollate broth and incubated for 24 hours in $37^{\circ} \mathrm{C}$. The broth was primarily examined for the presence of grown bacteria by a direct Gram-stained smear in the subsequent day. subculture was made for positive samples on chocolate agar, McConky agar, and blood agar and incubated in $37^{\circ} \mathrm{C}$ for 24 to 48 hours. then, the macroscopic and microscopic features was studied (study of shape and color of colonies and Gram staining) and based on their morphology, standard identification biochemical tests for Gram negatives including oxidase and catalase, reaction in triple sugar iron agar(TSI) medium, indole production and motility, urea utilization and catalase, coagulase and DNase tests for presence of staphylococci were performed (13).

Antimicrobial susceptibility testing was performed afterward in order to isolate bacteria by disk diffusion method as per Clinical and Laboratory Standards Institute (CLSI) standard guideline (14).The antibiotic discs which were used for Gram negative bacilli were: gentamicin $(10 \mu \mathrm{g})$, cefixime $(5 \mu \mathrm{g})$, ceftriaxone $(30 \mu \mathrm{g})$, ciprofloxacin $(5 \mu \mathrm{g})$,nalidixicacid

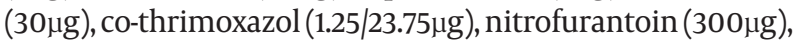
tetracycline $(30 \mu \mathrm{g})$, pipracillin $(100 \mu \mathrm{g})$, imipenem $(10 \mu \mathrm{g})$, and for Gram positive cocci were: cephalothin $(30 \mu \mathrm{g})$, cefixime $(5 \mu \mathrm{g})$, ceftriaxone $(30 \mu \mathrm{g})$, ciprofloxacin $(5 \mu \mathrm{g})$, clindamycin 


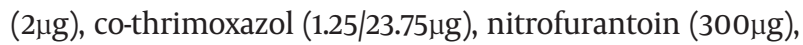
oxacillin $(1 \mu \mathrm{g})$, rifampin $(5 \mu \mathrm{g})$, vancomycin $(30 \mu \mathrm{g})$. The data were analyzed by descriptive statistics using SPSS version 17.

\section{Results}

From total investigated specimens, 278 had positive culture with 508 isolates. The positive specimens were belonged to 191 male and 87 female hospitalized patients. The majority of these specimens (40.3\%), were isolated from patients in age group of 18 to 40 years. Most of the samples were collected from intubated patients in ICU $(n=.112)$, and NICU $(n=107)$. Based on the bacteriology results, Enterobacter spp. with 209 cases (41.14\%) were the most prevalent genera isolated from positive cultures. The number and frequency of other isolated bacteria were:P. aeruginosa78 (15.35\%), E. coli71(13.97.2\%), coagulase negative staphylococci 75 (14.76\%), S. aureus71 (13.97\%), and proteus spp. 4 (0.79\%).

Antimicrobial susceptibility testing revealed that the most resistant Gram negative isolate was P.aeruginosa with highest resistance against cefixime (70.8\%) (Figure 1). Coagulase negative staphylococci (CoNS) was the most resistant Gram positive isolate with highest resistance against oxacillin (84.2\%) (Figure 2).The overall results of susceptibility testing are shown in Table 1.

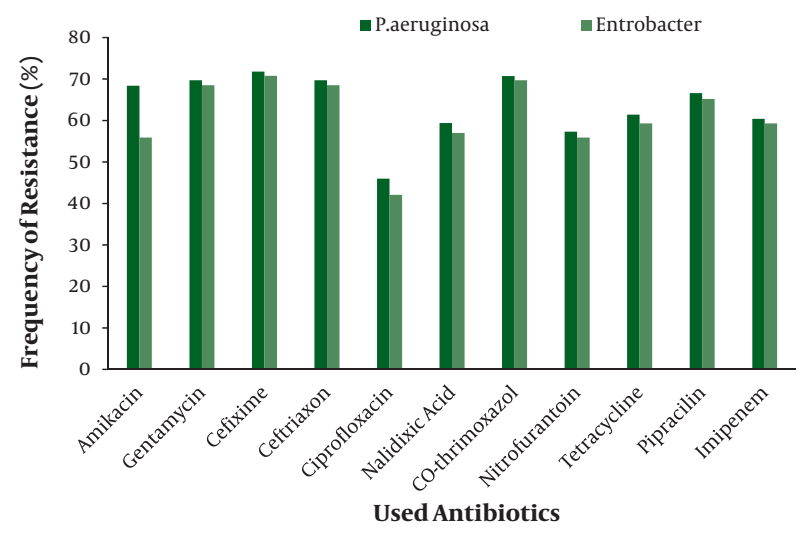

$\overline{\text { Figure 1. Resistance Patterns of Isolated Gram Negative Bacteria to Used }}$ Antibiotics

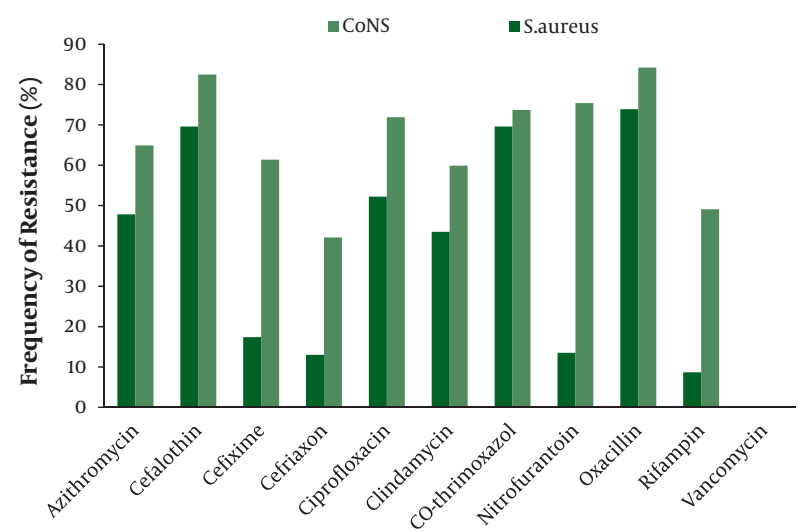

Figure 2. Resistance Patterns of Isolated Gram Positive Bacteria to Used Antibiotics

\section{Discussion}

Nosocomial infections are a serious concern in teaching hospitals in Ahvaz, Iran as many other parts of the world. Despite the careful managements of the wards by the infection control committee, we have still witnessed such infections due to several factors involved in emerging of infections, for instance employing intensive medical procedures especially for immune-compromised patients. In this study which was performed in some wards of the hospital, Enterobacter spp. and P. aeruginosa were the most prevalent bacteria isolated from tracheal tubes of the patients. In the study of Andair et al., Enterobacter spp., P. aeruginosa, and S.aureus were mostly isolated (15), which was in concordance with the present study, except for CoNS which was the most common Gram positive contaminant of tracheal tubes. However the study of Amini et al. was against the findings of the present study, which in overall they reported S. aureus as the most common isolate and enterobacter as the least one, isolated from tracheal tubes in Tehran (4).

In a similar study undertaken by Rahbar and Hajia in 2006, Gram negative bacteria were accounted for $75 \%$ of total positive cultures with Klebsiella pneumonia (20\%) and S. aureus (15.2\%) as the most prevalent Gram negative and

\begin{tabular}{|c|c|c|c|c|c|c|}
\hline Antibiotic & P.aeruginosa & E.coli & Entrobacter & Antibiotic & S.aureus & CoNS \\
\hline Amikacin & 68.4 & 62.4 & 55.9 & Azithromycin & 47.8 & 64.9 \\
\hline Gentamycin & 69.7 & 59.1 & 68.5 & Cefalothin & 69.6 & 82.5 \\
\hline Cefixime & 71.8 & 42.7 & 70.8 & Cefixime & 17.4 & 61.4 \\
\hline Ceftriaxon & 69.7 & 52.3 & 68.5 & Cefriaxon & 13 & 42.1 \\
\hline Ciprofloxacin & 46 & 52.7 & 42.1 & Ciprofloxacin & 52.2 & 71.9 \\
\hline Nalidixic Acid & 59.4 & 67.3 & 57 & Clindamycin & 43.5 & 59.6 \\
\hline Co-thrimoxazol & 70.7 & 64.5 & 69.7 & Co-thrimoxazol & 69.6 & 73.7 \\
\hline Nitrofurantoin & 57.3 & 53.6 & 55.9 & Nitrofurantoin & 13.5 & 75.4 \\
\hline Tetracycline & 61.4 & 60.7 & 59.3 & Oxacillin & 73.9 & 84.2 \\
\hline Pipracilin & 66.6 & 55.5 & 65.2 & Rifampin & 8.7 & 49.1 \\
\hline Imipenem & 60.4 & 44.5 & 59.3 & Vancomycin & - & - \\
\hline
\end{tabular}

Abbreviations: CoNS,Coagulae negative staphylococci 
Gram positive isolates respectively (16). While the frequency of enterobacter was $41.14 \%$ in this study, they have reported the frequency of $3 \%$ for the same bacterium, although the frequency of S. aureus in their study with $15.2 \%$ was slightly higher but close to the present work (13.97\%). This shows the variety of bacteria isolated from different hospitals and different periods of time and depends on many factors.

During the study, it was noticed that most of investigated hospital wards were colonized by mentioned bacteria, though the highest colonization was belonged to general ICU and NICU. This is a matter of concern, since the patients hospitalized in these units are seriously ill or due to age or immunological status are more prone to get infections. Both isolated Gram negative bacteria are responsible for serious infections. In case of Enterobacter spp., it may cause infections including bacteremia, lower respiratory tract, skin and soft-tissue infections (17). Besides, $P$. aeruginosa as a main opportunistic pathogen comprises potential capacity to cause nosocomial infections which affects a remarkable number of patients in ICU. The importance of this bacterium is that it shows a high antibiotic resistance, so it is able to cause severe infections in critically ill patients associated with substantial morbidities and mortality $(18,19)$. Subsequently in the present study P. aeruginosa isolates were highly antibiotic resistant and apart from other antibiotics, showed $60.4 \%$ resistance to Carbapenem antibiotics. This was higher than the rate reported by Gladestone et al. for this bacterium in their study (20). Colonization of this organism in different parts of hospitals is a common concern worldwide, and there are reports of severe infections caused by highly antibiotic resistant $P$. aeruginosa strains in ICU and other wards of hospitals $(18,21)$.

In the latter study, the origin of the organism was the water outlets. In present study, enterobacter was the most prevalent isolate with relatively high antibiotic resistance. This finding was similar to other studies in which drug resistant Gram negative bacteria has been reported to isolate frompatients in ICUs (21). In a recent study, non fermenting bacteria such as acinetobacter spp. were among the isolates from ICU patients (20), while no acinetobacter was isolated from samples in this study. Based on investigations, the potential factors enhancing the emergence of resistant bacteria in hospitalized patients are mainly duration of stay in intensive care wards, using mechanical devices, prior antibiotics use, especially broad-spectrum drugs such as third-generation cephalosporin, fluoroquinolone, and/or imipenem (22). Many patients in the present work had a history of such antibiotics consumption.

In summary, the findings of this study indicate the emergence of antibiotic resistant infections in our hospital wards especially ICU and NICU and there is still a need to improve the effectiveness of integrated infection control programs focused on HAI surveillance in teach- ing hospitals under investigation to control and manage nosocomial infections caused by highly resistant organisms.

\section{Acknowledgements}

We would like to thank the staff of central laboratory of Golestan teaching hospital, for providing the samples. Special thank goes to Miss Manijeh Mehdinejad for her assistance in graphic works.

\section{Financial Disclosure}

None declared.

\section{Funding/Support}

None declared.

\section{Authors' Contribution}

None declared.

\section{References}

1. Peleg AY, Hooper DC. Hospital-acquired infections due to Gramnegative bacteria. N Engl J Med. 2010;362(19):1804-13.

2. Bagheri Nejad S, Allegranzi B, Syed SB, Ellis B, Pittet D. Healthcare-associated infection in Africa: a systematic review. Bull World Health Organ. 2011;89(10):757-65.

3. World Health Organization. Prevention of hospital-acquired infections: a practical guide. World Health Organization, Geneva, Switzerland. 2002.

4. Amini M, Javanmard A, Davati A, Azimi G. Bacterial Colonization in Tracheal Tubes of ICU Patients. Iran J Pathol. 2009;4(3):123-7.

5. Rosenthal VD, Maki DG, Rodrigues C, Alvarez-Moreno C, Leblebicioglu $\mathrm{H}$, Sobreyra-Oropeza $\mathrm{M}$, et al. Impact of International Nosocomial Infection Control Consortium (INICC) strategy on central line-associated bloodstream infection rates in the intensive care units of 15 developing countries. Infect Control Hosp Epidemiol. 2010;31(12):1264-72.

6. Nseir S, Grailles G, Soury-Lavergne A, Minacori F, Alves I, Durocher A. Accuracy of American Thoracic Society/Infectious Diseases Society of America criteria in predicting infection or colonization with multidrug-resistant bacteria at intensive-care unit admission. Clin Microbiol Infect. 2010;16(7):902-8.

7. Chastre J, Fagon JY.Ventilator-associated pneumonia.Am J Respir Crit Care Med. 2002;165(7):867-903.

8. Niederman M, Craven D, Bonten M, Chastre J, Craig W, Fagon J, et al. Guidelines for the management of adults with hospitalacquired, ventilator-associated, and healthcare-associated pneumonia. Am J Respir Crit Care Med. 2005;171(4):388-416.

9. Nseir S, Ader F, Lubret R, Marquette $\mathrm{CH}$. Pathophysiology of airway colonization in critically ill COPD patient. Curr Drug Targets. 2011;12(4):514-20.

10. Gruson D, Hilbert G, Vargas F, Valentino R, Bebear C, Allery A, et al. Rotation and restricted use of antibiotics in a medical intensive care unit. Impact on the incidence of ventilator-associated pneumonia caused by antibiotic-resistant Gram-negative bacteria. Am J Respir Crit Care Med. 2000;162(3 Pt 1):837-43.

11. Rosenthal VD, Maki DG, Salomao R, Moreno CA, Mehta Y, Higuera F, et al. Device-associated nosocomial infections in 55 intensive care units of 8 developing countries. Ann Intern Med. 2006;145(8):582-91.

12. Rosenthal VD. Device-associated nosocomial infections in limited-resources countries: findings of the International Nosocomial Infection Control Consortium (INICC). Am J Infect Control. 
2008:36(10):S171 e7-12

13. Forbes S, Sahm D. Weissfeld AS. Bailey \& Scott's diagnostic microbiology. 12 ed. Inc.,St. Louis. Mo: Mosby;2007.

14. Watts JL. Clinical Laboratory Standards Institute, Performancestandards for antimicrobial susceptibility testing, 12th InformationalSupplement. Pennsylvania, USA. Clinical and Laboratory Standards Institute (CLSI); 2008.

15. Adair CG, Gorman SP, Byers LM, Jones DS, Feron B, Crowe M, et al. Eradication of endotracheal tube biofilm by nebulised gentamicin. Intensive Care Med. 2002;28(4):426-31.

16. Rahbar M, Hajia M. Detection and quantitation of the etiologic agents of ventilator-associated pneumonia in endotracheal tube aspirates from patients in Iran. Infect Control Hosp Epidemiol. 2006;27(8):884-5.

17. Boban N, Punda-polic V. Outbreak of nosocomial bacteremias, caused by Enterobacter gergoviae and Enterobacter aerogenes, in the neonatal intensive care unit, case - control study. Signa Vitae. 2011;6(1):27-32.
18. Slama KB, Jouini A, Maarouf M, Fendri C, Boudabous A, Gtari M. Epidemiology of Pseudomonas aeruginosa in Intensive Care Unit and Otolaryngology Department of a Tunisian hospital. Afr J Microbiol Res 2011;5(19):3005-11.

19. Vincent JL. Nosocomial infections in adult intensive-care units. Lancet. 2003;361(9374):2068-77.

20. Gladstone P, Rajendran P, Brahmadathan KN. Incidence of carbapenem resistant nonfermenting Gram negative bacilli from patients with respiratory infections in the intensive care units. Indian J Med Microbiol. 2005;23(3):189-91.

21. Trautmann M, Lepper PM, Haller M. Ecology of Pseudomonas aeruginosa in the intensive care unit and the evolving role of water outlets as a reservoir of the organism. Am J Infect Control. 2005;33(5 Suppl 1):S41-9.

22. Trouillet JL, Chastre J, Vuagnat A, Joly-Guillou ML, Combaux D, Dombret MC, et al. Ventilator-associated pneumonia caused by potentially drug-resistant bacteria. Am J Respir Crit Care Med. 1998;157(2):531-9. 